\title{
Value Chain Mapping of Tourism in Birbhum
}

\author{
Debdip Khan, Burdwan Raj College, India \\ Sudatta Banerjee, University Institute of Technology, India
}

\begin{abstract}
Tourism is one of the most enhancing and continuous developing economic sectors throughout the world. The main objective of the study is to develop a proper value chain mapping on Birbhum tourism, along with generation of different strategies for the integration of other variable resources with local communities. The study also aims at developing different maps on tourism value chain along with some distinct sub-chains in the entire Birbhum district. Local development of Birbhum tourism can be possible through proper value chain mapping. Through mapping of proper value chain, Birbhum tourism will gradually develop as a major strength of West Bengal's economic development. In this paper, the authors addressed the relationship between the supply of products from firm level to tourist in the tourist spot and the impact of value chain mapping (VCM). The current work emphasizes on the enhancement of the local tourism through uninterrupted activities of VCM, developing the socioeconomic structure of the tourism through flow of proper VCM.
\end{abstract}

\section{KEYWORDS}

Mapping Methodology, Tourism Industry, Tourism Supply Chains, Value Chain, Value Chain Mapping

\section{INTRODUCTION}

Value chain mapping is a process that identifies the main activities associated with service or product line and is often used in corporate strategy in order to identify performance improvement opportunities. Porter (1989) defines the value chain as a combination of several activities which include design, production, delivery and sustainability. According to Kaplinsky and Morris (2001), by mapping the value chain it is possible to understand the value added flow for that particular product or service line. It exists on every step from the concept generation, through the steps of production or service to till the end to the customer. Yun (2004) concentrated on knowledge management in hospitality and tourism sector.

Value chain is a sequence of activities which are closely interrelated among one another and they are connected in such a way that they can add value to the product or service line (Dicken, 2007). Roy and Khan (2010) proposed integrated model for line balancing with workstation inventory management. Song et al. (2013) reviewed Tourism value chain governance and Tribe \& Liburd (2016) developed the knowledge system for tourism. Ndyetabula et al. (2016) worked on different level of value chain and identified various actors of the chain. Network approach to tourist segmentation was also done (Hernandez et al., 2018) and sustainability part was also taken care of (Banerjee \& Khan, 2019)

But all the works were mainly on the organizational value chain. Very few works have been done on service industry like tourism. Even there is no proper methodology for value chain mapping. Here a research gap has been identified and the authors have tried to work in this particular area. In this

\section{DOI: 10.4018/IJTHMDA.2020070103}

This article, originally published under IGI Global's copyright on July 2, 2020 will proceed with publication as an Open Access article starting on January 20, 2021 in the gold Open Access journal, International Journal of Tourism and Hospitality Management in the Digital Age (converted to gold Open Access January 1, 2021), and will be distributed under the terms of the Creative Commons Attribution License (http://creativecommons.org/licenses/by/4.0/) which permits unrestricted use, distribution, and production in any medium, provided the author of the original work and original publication source are properly credited. 
current work the authors proposed value chain mapping in the tourism service sector, formulated methodology and strategy for value chain mapping in Tourism and implemented it in Birbhum district of West Bengal in India.

\section{OBJECTIVES}

The major objective of our study is to propose the Value Chain Mapping (VCM) methodology of tourism in Birbhum district of West Bengal. The authors have also tried to formulate strategies for integrating all elements in the value chain.

1. The primary objective of this paper is to enhance the local tourism through the proper mapping of the tourism value chain of Birbhum

2. To specify all the sub-chains associated with the main value chain.

3. To develop the socio economic structure of the tourism through flow of proper VCM.

4. To develop efficient techniques and measures for improving value chain linkage in Birbhum tourism sector.

5. To identify opportunities and threats and suggest strategies for specific value chain.

6. To influence policies for local development and tourism in Birbhum.

\section{METHODOLOGY}

The research approach is qualitative. Authors have focused on interpretation rather than quantification. It is based on subjectivity rather than objectivity, on process orientation rather than results and on context since the behavior of the people involved and the situation are based on experience formation (Cassel \& Symon, 1994).

The methodology followed here is a three-stage process. The first phase is destination research. This phase is based on a holistic approach. In this phase the authors tried to achieve a holistic understanding of tourism in Birbhum. To identify the key stakeholders involved in tourism in Birbhum, we have reviewed the literature. Desktop researchs have been done also. The process continued with some open-end interviews. Stratified random sampling procedure is used for that purpose. Based on that the authors have tried to identify the various factors and forces which have the key roles in tourism value chain. The gaps between various factors of value chain have been identified and linkages have been established. Triangulation method was adopted. The collected information helped to study the current weakness of the value chain and indicated where the mapping can be done to bring effective changes.

\section{AN OVERVIEW OF TOURISM IN BIRBHUM}

Birbhum is located in the state of West Bengal surrounded by Murshibad and Jharkhand in the north, Murshibad in the east, Jharkhand in west and Purba Bardhaman and Paschim Bardhaman in the south. The region is famous for its cultural heritage of Tagore and different local culture, Boul Sangeet along with natural scenic beauty of its unique red soil.

\section{MAJOR TOURISM PRODUCTS IN BIRBHUM}

- Culture Tourism: Most important and famous tourism product of Birbhum. It includes Santiniketan, Bolpur, Joydev-Kenduli and its different festivals and fairs. 
Figure 1. Three stage of methodology

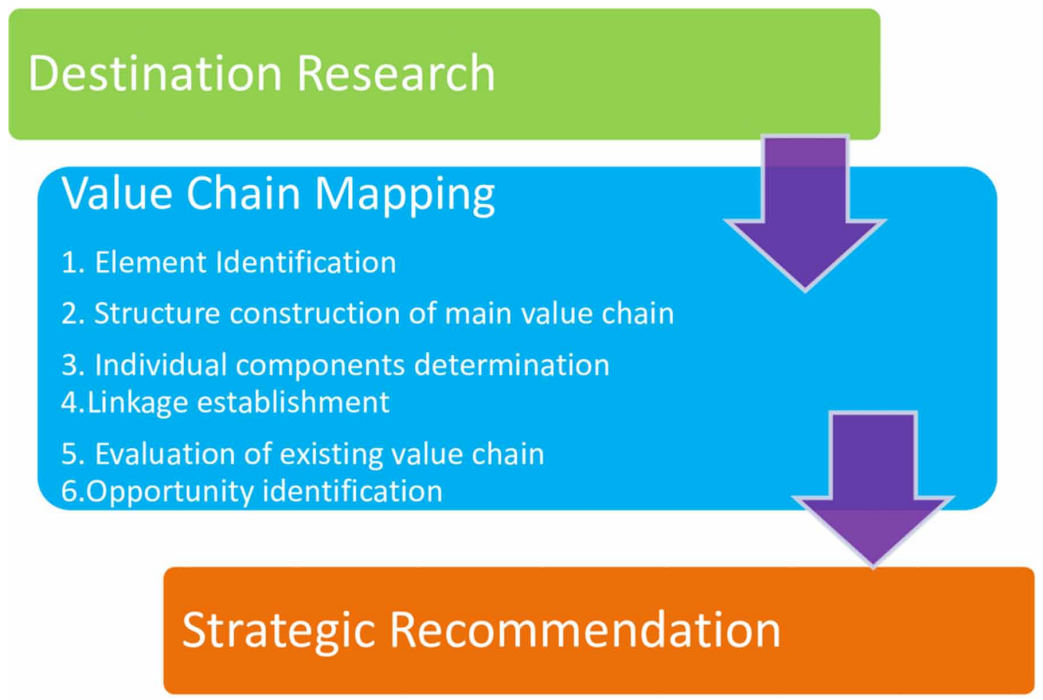

Figure 2. Location of Birbhum
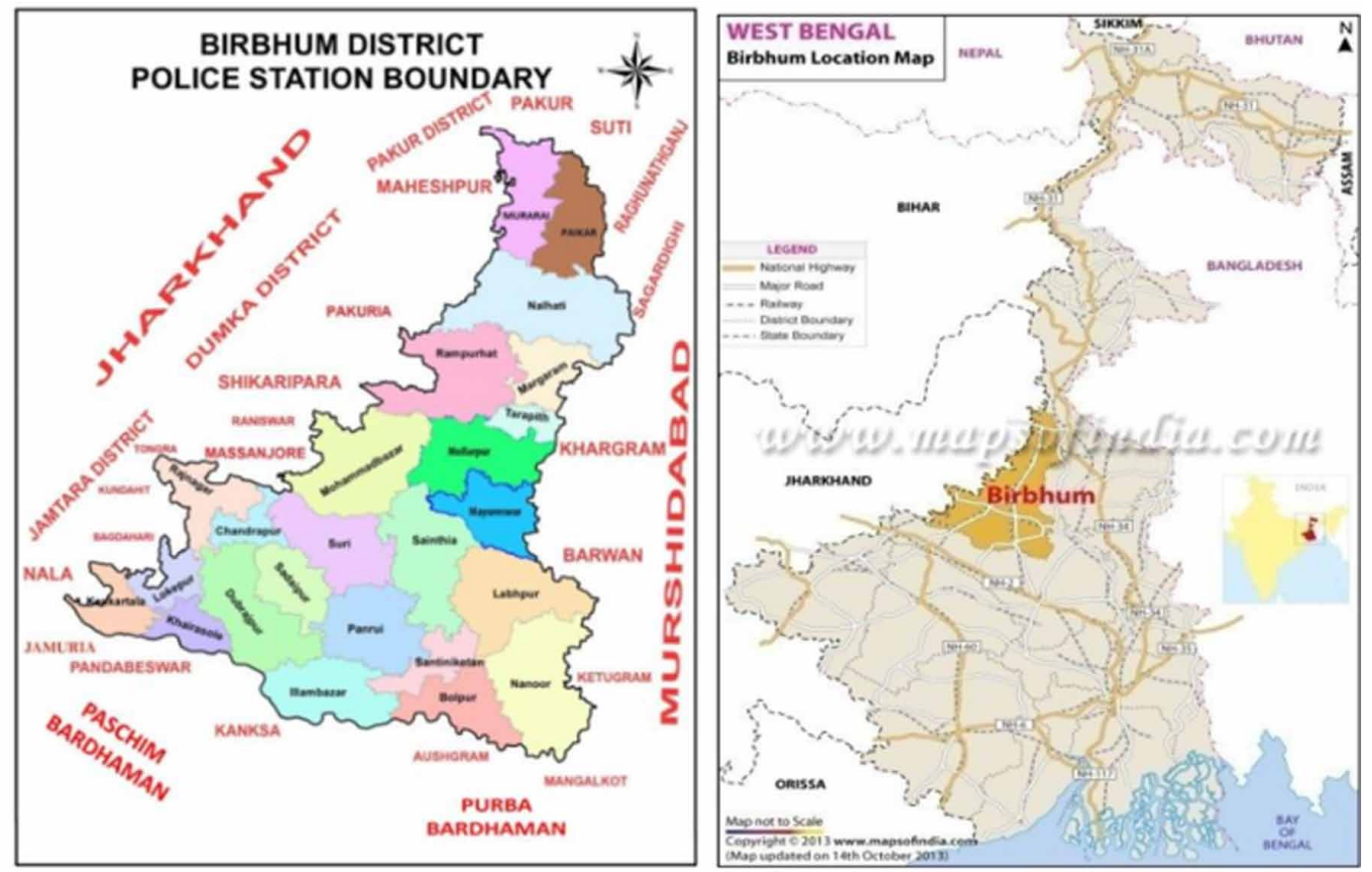

- Religious Tourism: Tarapith, Bakreswar, Patharchapuri, Kankalitala, Fullura Devi Saktipeeth at Labhpur, Ekachakra Village, Nalateswari Temple Satipeeth at Nalhati, Nandikeshwari Temple at Sainthia, Radhamadhav temple at Joydev-Kenduli, Bhandier Bon, 
- Nature Tourism: Dubrajpur, Heamatpur, Amkhoi Fossil Park near Illambazar, Ballabhpur wildlife sanctuary.

Growth of Tourism in Birbhum: As per the annual report of the Tourism Survey, West Bengal (201516) tourist in Birbhum district was 247818. Among the tourist number of domestic tourist was 247686 and the rest 132 was foreign tourist. As per Municipal sources, considerable growth in the number of tourist flow has been observed in the recent years.

Rapid development of Birbhum on account of tourism is degrading the ecosystem of Birbhum. There is a huge expansion of infrastructure for accommodating rapidly grown number of tourists. These modern tourists consume more resources which is hampering local ecosystem and causing degradation and over exploitation.

Local communities face severe hardship because of extensive use and maleficent of ecosystem with the scarcity of natural resources. Therefore behind every tourism operation in Birbhum we have to consider a number of variables along with local communities and different stakeholders. One of the very important part in central value chain is resource distribution. This has to be properly compatible with the co-functioning of stakeholders. All the concerned stakeholders are interlinked in securing the aspect of tourism value chain.

\section{Key Stakeholders in Tourism in Birbhum}

- Government Agencies: Ministry of Tourism, Government of India; West Bengal Tourism Department, Department of Wildlife and Forest.

- Local Business: Hotels and guest houses, Home stays, Restaurants and food stalls, Travel agents, Tour operators, Transport, Handicrafts, local jewellery, traditional souvenirs,

- Local Community: Local tour guides, cab drivers, rickshaw pullers, hotel staff, local shop owners etc

Both the centre government and state government are the key stakeholders. Mainly they are responsible for policies related to tourism. The operational structure of the tourism sector is constituted by other stakeholder groups such as local business enterprises, and industry associations. The local communities provide resources, labour and knowledge. It is obvious that not all the stakeholders are equally important and influential in tourism value chain.

We have analyzed the Birbhum tourism value chain and developed a proper value chain mapping of various roles of stakeholders.

\section{TOURISM VALUE CHAIN ANALYSIS FOR BIRBHUM}

Tourism industry is a service Industry. It is basically people oriented. Tourism value chain consists of businesses and organizations from different sectors. In a tourism value chain, we have different areas like hospitality, travel and various other businesses. Proper interconnection and coordination among those various business sectors can offer a good travel experience.

Tourism industry will grow if more stakeholders will engage. Destination resources should be utilized with an understanding in such a way that it leads to mutual gain across the sector. This will create infrastructure. It will also create employment opportunities for the local people. The socio economic structure of the locality is developed from the direct income from tourists. Among the different destinations tourism can be used as a unique tool to transfer resources. This benefit should be distributed properly across the tourism chain and therefore Tourism value chain analysis has a very crucial role in the development of Tourism industry.

The tourism sector in Birbhum has largely developed by the massive inflow of tourists. It causes major changes in the economic and environmental aspects of the region. There should be a positive 


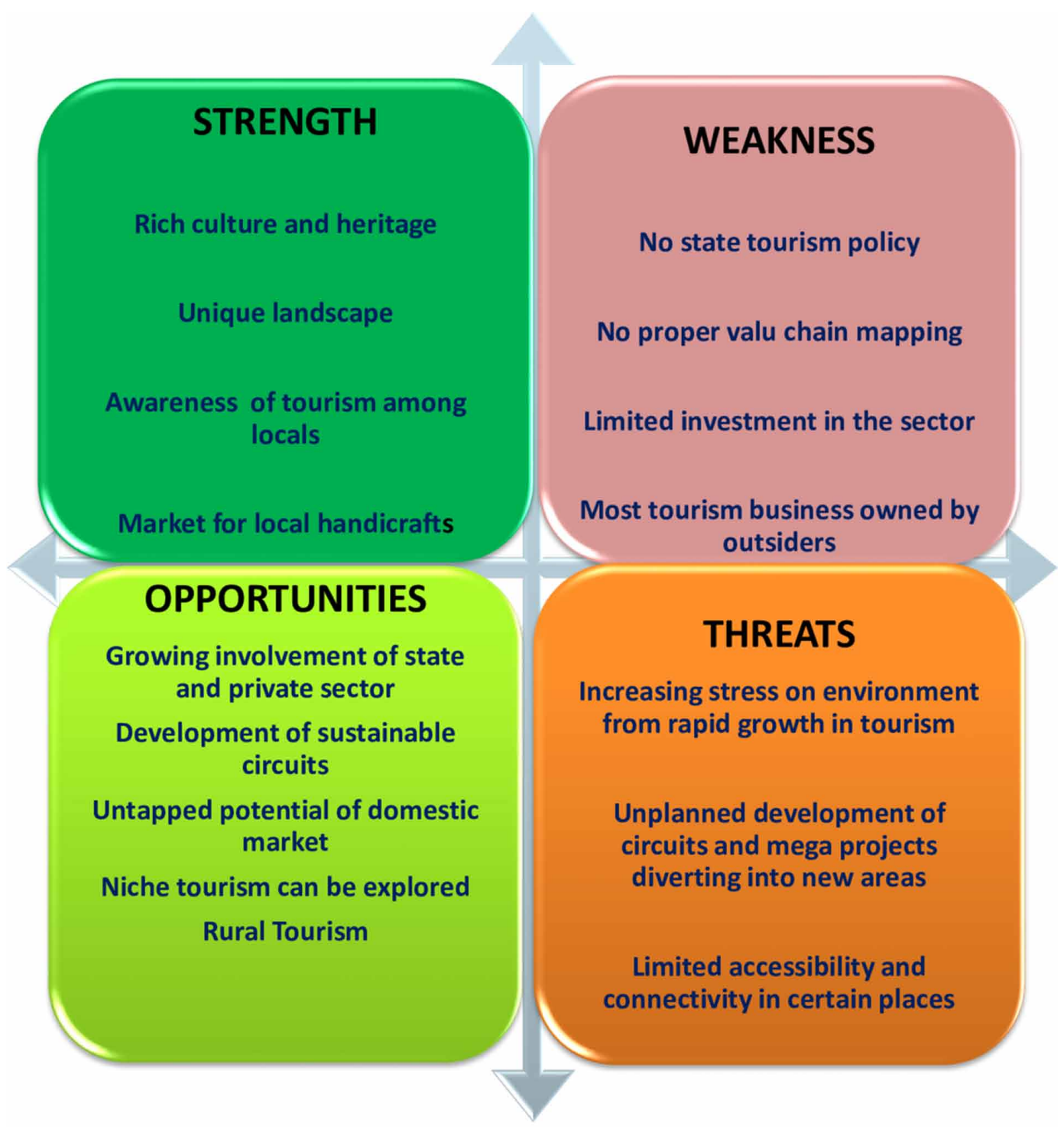

reaction from local people to accommodate the increasing inflow of tourists. Income distribution, resource utilization and other tangible benefits are the others major concern. Understanding the relevance of different stakeholders, a tourism value chain analysis has been carried out for Birbhum.

The existing tourism model, Birbhum have highly diversified tourism products. Religious and culture tourism have their own tourist base. But from the discussions it is revealed that the demands for other kind of tourism, like wildlife tourism or Nature tourism are high now.

The tourism value chain is mainly controlled and influenced by state governments and central government's Tourism Department, West Bengal Forest Department, and some local authorities.

Analyzing the existing tourism value chain for Birbhum the authors suggests that the needs of poor and the marginal groups should be taken into account along with promoting private investment, macro-economic growth and foreign exchange earnings. It is also very clear from the analysis that 
Figure 4. Key component of tourism industry

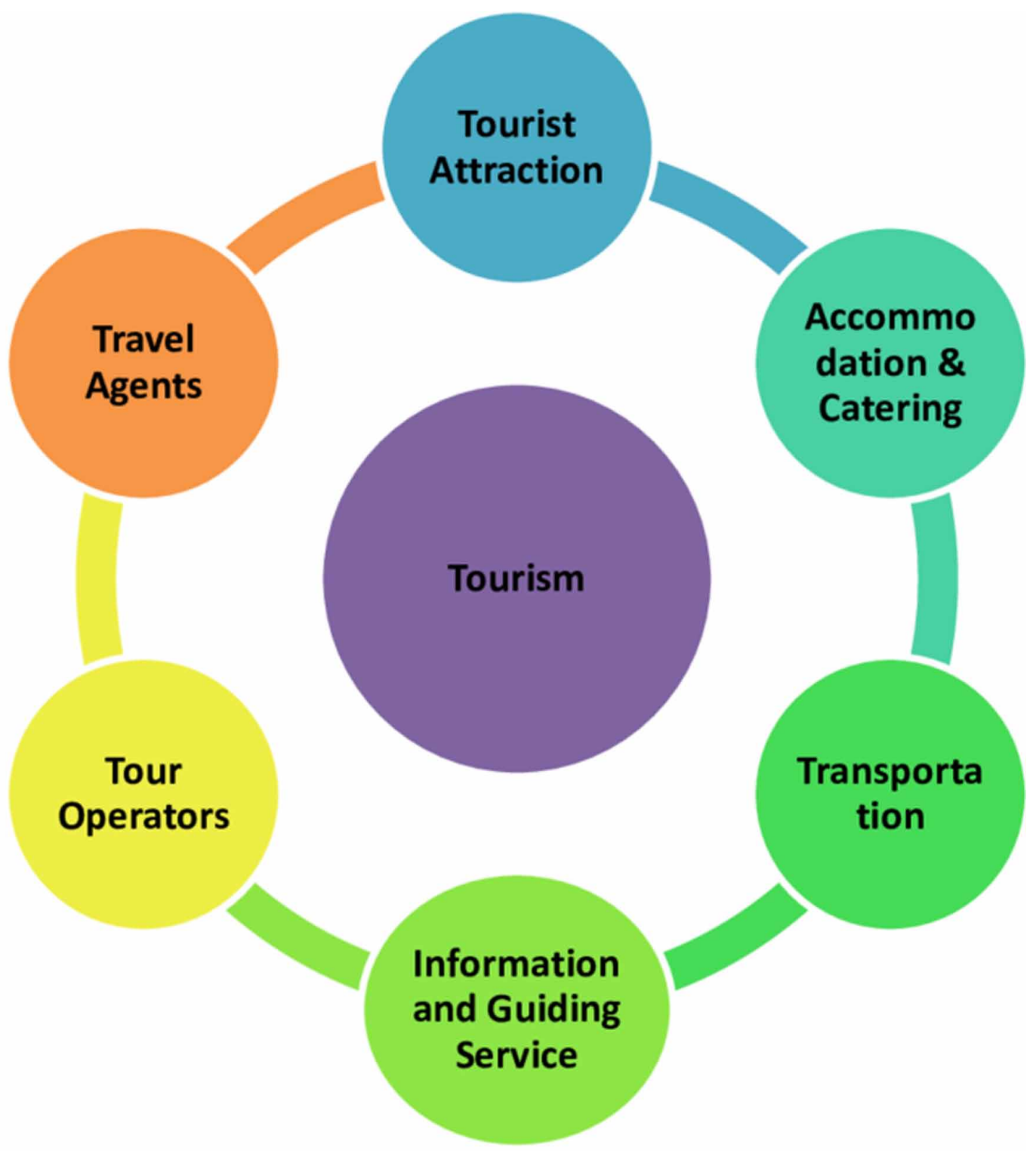

the bulk amounts of various benefits are mainly boosting the outsiders. Only very few people of the locality is getting benefitted.

\section{VALUE CHAIN MAPPING OF TOURISM IN BIRBHUM}

- Adapting a Pro-Poor Approach in Tourism: Pro-poor tourism (PPT) is defined as tourism that generates net benefits for the poor. Conceptually, pro- poor tourism integrates local communities into the process for the purpose of generating net benefits for poor and disenfranchised local communities (Ashley, et al., 2001). Here the main concept is benefits generated from tourism directly go to poor communities. Poor people are always at the centre of the model. The main 
Figure 5. Tourism value chain analysis in Birbhum

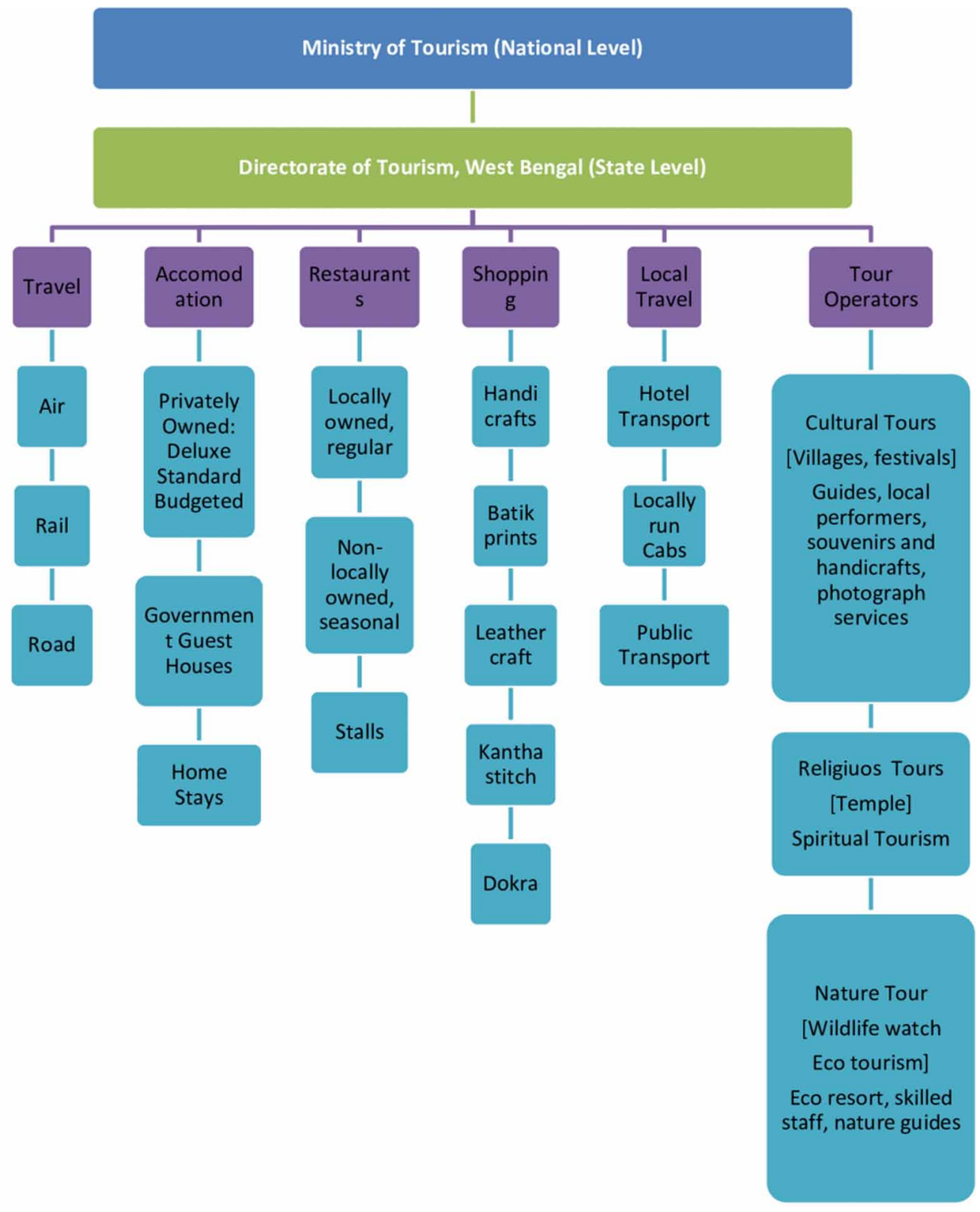

objective is to increase economic benefits for the poor. It is done through expanding business and employment opportunities. Negative social and environmental impacts are minimized. New policy and process frame work is created for removing barriers to the poor by promoting participation of the poor in planning and decision-making processes. Partnerships between private sector and the poor are to be developed.

The process and the role of different stakeholders in pro- poor tourism may be summarized as follows 


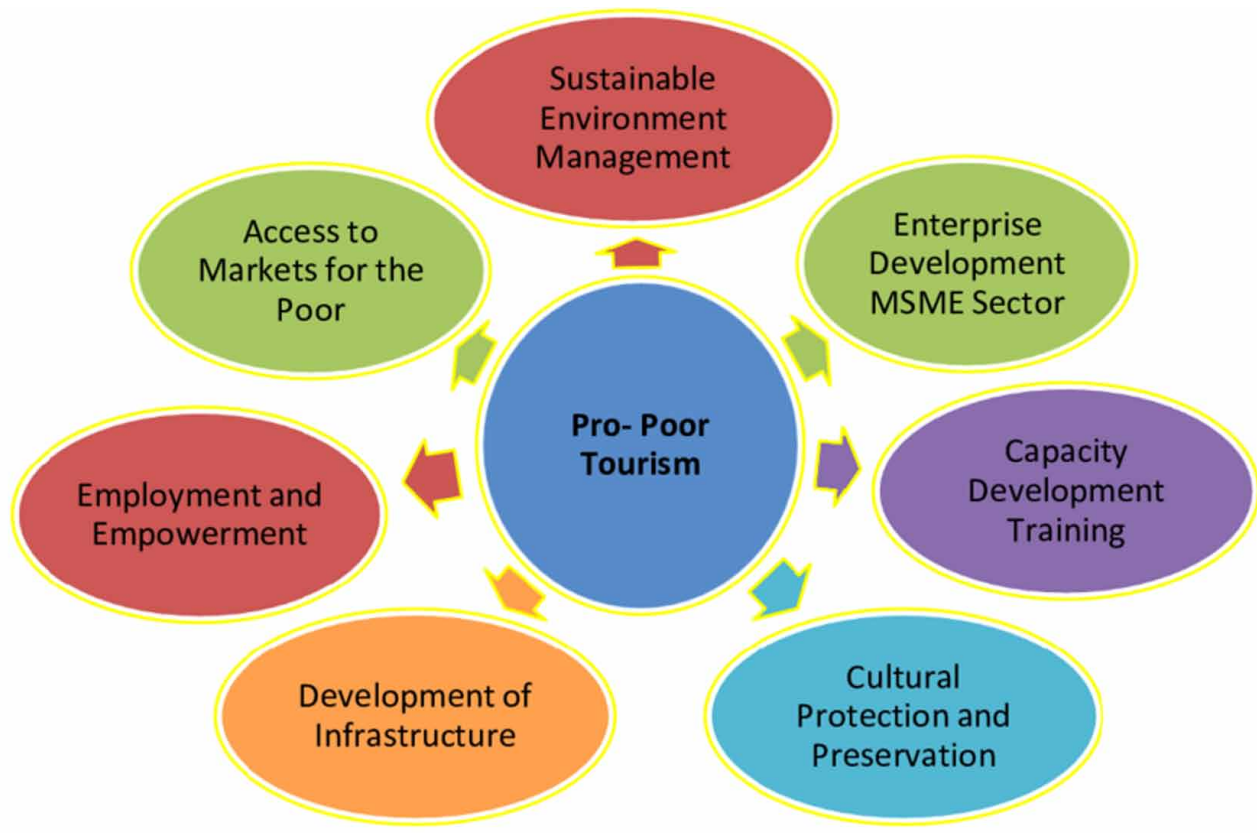

Figure 7. Different stakeholders in pro- poor tourism
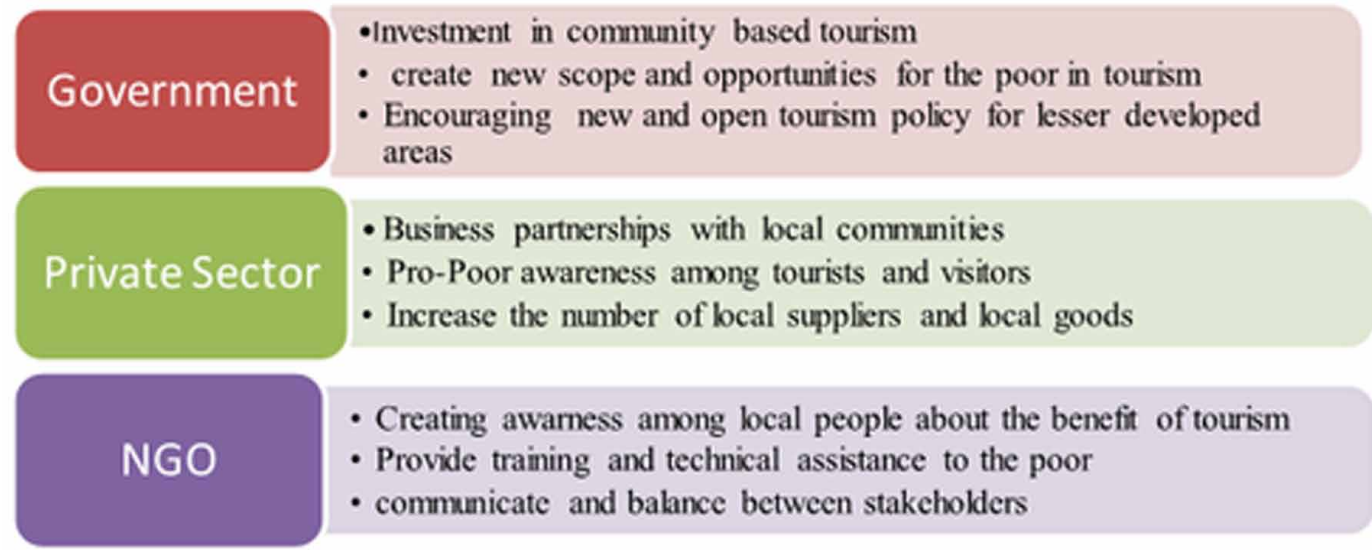

- Creating awarness among local people about the benefit of tourism

- Provide training and technical assistance to the poor

- communicate and balance between stakeholders 
Figure 8. Tourism value chain mapping in Birbhum

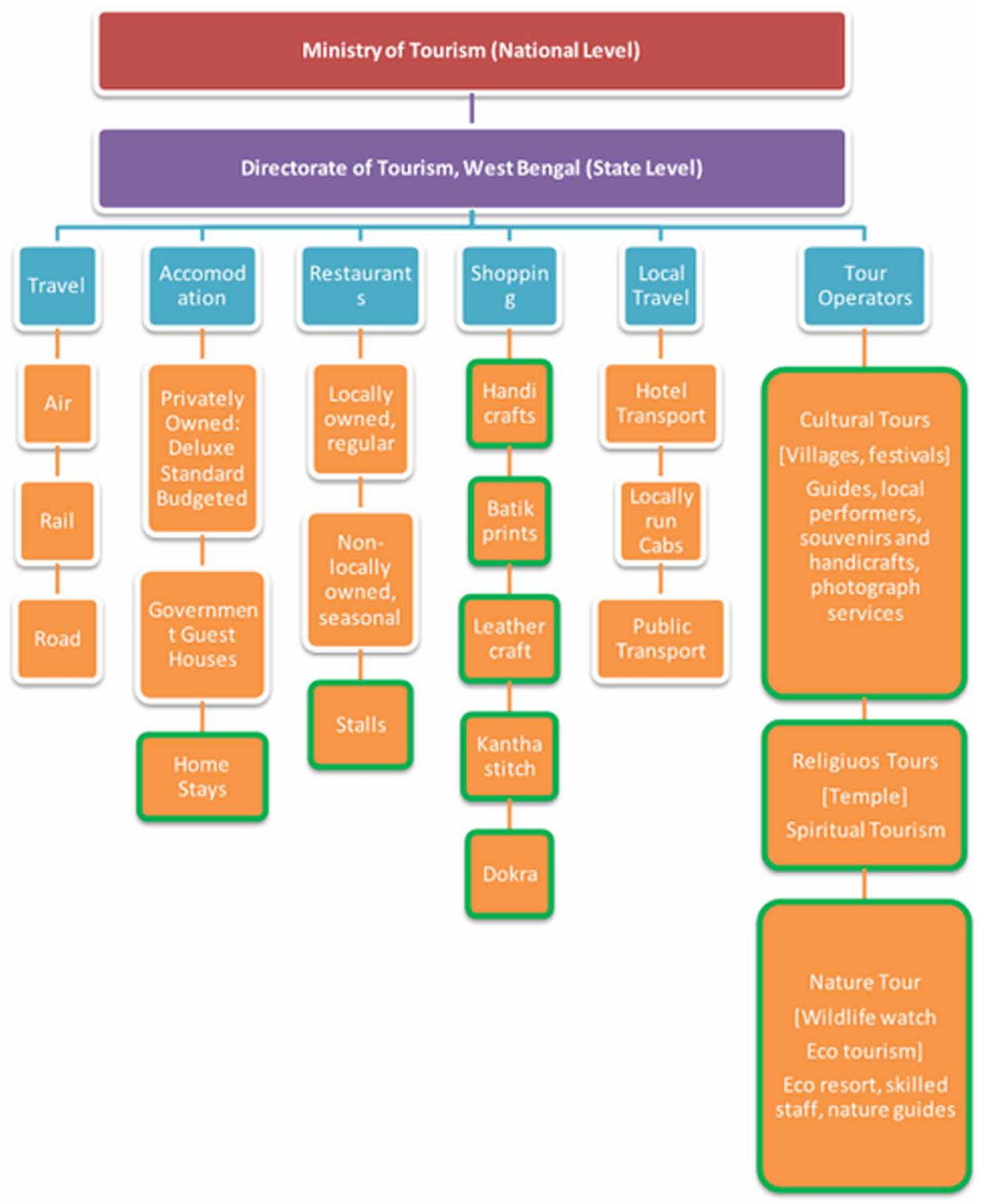

The involvement opportunities of the poor people are shown by green bordered areas on the existing value chain

\section{CONCLUSION}

Birbhum Tourism has great opportunities for sustainable, pro-poor development. As a destination, Birbhum is capable of supporting such pro-poor tourism opportunities across its value chain. This 
pro-poor tourism will create sustained employment and opportunities for the poor people, women and marginal communities.

There is a great scope for eco tourism and community tourism in Birbhum. This is going to be very vital part of tourism in Birbhum. Pro-poor tourism is to ensure that tourism should not be harmful to the local environment and culture on which it is dependent. Those valuable resources should not be destroyed. Now the biggest challenge is the integration of poor communities and people within these sustainable models. And if it is done, it will help towards poverty alleviation in a destination site and also provide a huge socio economic benefit in large scale to the entire Birbhum. 


\section{REFERENCES}

Ashley, C., Goodwin, H., \& Roe, D. (2001). Pro-Poor Tourism Strategies: Expanding Opportunities for the Poor. Centre for Responsible Tourism, Overseas Development Institute.

Banerjee, S \& Khan, D. (2019, Mar.). Sustainability of Tourism highly depends on conservation of nature in this globalised era. Research Directions, 163-167.

Dicken, P. (2007). Global shift: Mapping the changing Contours of the World Economy (4th ed.). Academic Press.

Hernandez, J. M., Kirilenko, A. P., \& Stepchenkova, S. (2018). Network approach to tourist segmentation via user generated content. Annals of Tourism Research, 73, 35-47. doi:10.1016/j.annals.2018.09.002

Kaplinsky, R., \& Morris, M. A. (2001). Handbook of Value Chain Research. Academic Press.

Ndyetabula, D. W., Sorensen, O. J., \& Temu, A. A. (2016). Agribusiness development and the role of value chain business association, The case of dried fruits and vegetables in Tanzania. African Journal of Economic and Management Studies, 7(2), 510-534. doi:10.1108/AJEMS-01-2014-0005

Porter, M.E. (1989). Vantagem Competitativa das Nacoes. Academic Press.

Roy, D., \& Khan, D. (2010). Integrated model for line balancing with workstation inventory management. International Journal of Industrial Engineering Computations., 1(2), 139-146. doi:10.5267/j.ijiec.2010.02.003

Song, H., Liu, J., \& Chen, G. (2013). Tourism value chain governance: Review and prospects. Journal of Travel Research, 52(1), 15-28. doi:10.1177/0047287512457264

Tribe, J., \& Liburd, J. J. (2016). The tourism knowledge system. Annals of Tourism Research, 57, 44-61. doi:10.1016/j.annals.2015.11.011

Yun, D. (2004). Knowledge management in hospitality and tourism. Annals of Tourism Research, 31(4), 1063-1065. doi:10.1016/j.annals.2004.04.004

Debdip Khan, PhD, MBA (systems), BE(CSE), is working as a lecturer in BBA BCA department in Burdwan Raj College Have 8 full length papers, Attended 4 international seminar, Member of UG studies in the university of Burdwan. Presently working as teacher in charge.

Sudatta Banerjee, PhD, MBA(hr), B.Sc with Physics, Chemistry, and Biology, works as a part time guest faculty since 2015 in University Institute of Technology. Working as a guest in the University of Burdwan. Working as a guest faculty in Burdwan Raj College. Attended 12 international and 4 national conferences. Author of 10 papers. 